\title{
Mediating Effect of Social Media Marketing Adoption Towards Business Performance: An Approach of Structural Equation Modelling Partial Least Square (SEM-PLS)
}

\author{
Muhammad Faizal Samat ${ }^{1}$, Mohd Nor Hakimin Yusoff $^{2}$, Mohammad Ismail ${ }^{2}$, Nur Amalina Awang ${ }^{3}$ \& Norazlan \\ Anual $^{4}$ \\ ${ }^{1}$ Malaysian Academy of SME and Entrepreneurship Development, Universiti Teknologi MARA, Malaysia \\ ${ }^{2}$ Faculty of Entrepreneurship and Business, Universiti Malaysia Kelantan, Malaysia \\ ${ }^{3}$ Akademi Pengajian Bahasa, Universiti Teknologi MARA Cawangan Kelantan, Malaysia \\ ${ }^{4}$ Faculty of Business and Management, Universiti Teknologi MARA Cawangan Melaka, Malaysia \\ Correspondence: Muhammad Faizal Samat, Malaysian Academy of SME and Entrepreneurship Development, \\ Universiti Teknologi MARA, Malaysia. Tel: 60-12-676-7825. E-mail: faizal951@uitm.edu.my
}

Received: June 17, 2020

doi:10.5430/rwe.v11n5p100
Accepted: August 17, 2020

Online Published: September 3, 2020

URL: https://doi.org/10.5430/rwe.v11n5p100

\begin{abstract}
Business environment in Malaysia has become more competitive due to the advancement of technology and globalisation including the small and medium enterprises (SMEs). SMEs have so long devised various marketing strategies in order to penetrate the online advertisement clutter alongside improving their performance. Past studies have shown that using ICT such as social media help to improve SMEs' performance. The owner-managers themselves determine the adoption of social media in their marketing due to the process of information collection and analysis are highly relied on them. Most of the SMEs have their own websites but these are primarily used as an information tool only. Thus, this study investigated the mediating role of social media marketing adoption between technological support, organisational support, government support and competitive intelligence towards the performance of SME. The theoretical framework of this study is substantiated by Resource-based View (RBV) theory and supported by Technology, Environment and Organisation (TOE) framework. This study has been carried out in the East Coast region of Malaysia consisting of Kelantan, Terengganu and Pahang states and also employed a questionnaire survey method. From 1920 questionnaires distributed, 339 responses were returned and found usable for the final analysis using the structural equation model partial least square (SEM-PLS). The findings revealed that the adoption of social media marketing mediates the relationship between these technological, organisational, and government supports, the competitive intelligence, and SME performance. Finally, the study's theoretical and practical implications as well as the limitations and directions for future research were provided and discussed.
\end{abstract}

Keywords: technological support, organisational support, government support, competitive intelligence, social media marketing, business performance

\section{Introduction}

The booming of technology has not only transformed how people communicate, looking at the massive use of social media among the consumers in particular, but also leading the business makers to seize this online market segment as potentially more lucrative. Ricciardelli, Nackerud, Quinn, Sewell and Casiano (2020) defined the social media as an extensive assembly of applications run over the internet and powered by the users themselves; as they contribute to both the content creation as well as exchange. The six various forms of social media, as adapted from Grahl (2016), include (i) social networking sites like Facebook, (ii) bookmarking sites like del.icio, (iii) micro blogging sites like Twitter, (iv) media sharing sites like YouTube, (v) social news sites like Reddit, and (vi) blogs and forums like Wordpress. According to zdnet.com as cited in Samat, Hashim, and Yusoff (2015), the International Data Corporation (IDC) analyst noted two factors which have contributed to the rise of social media's phenomenon: eyeballs and relevance. "Advertisers will always go where the eyeballs are - where people will see advertisements," he explained. "As people spend more time online and less on the traditional media, it makes sense to move online because the Internet is a much better (and vastly bigger) platform for getting your advertisements to reach relevant 
eyeballs". Therefore, the business makers realised the crucial need to develop and maintain an active website to serve their business purposes since missing out on these marketing opportunities would place them at a disadvantage. This has introduced the "social media marketing" realm in which the business makers now establish their presence on major social media platforms. Primarily, the nature of marketing remains, as they reach out to a targeted audience yet with the creation of web-based contents tailored specifically to their respective group of customers. These contents on the companies' website are then made shareable on the social media, followed by communicating with their clients using that very platforms (Siamagka, Christodoulides, Michaelidou, \& Valvi, 2015). By default, communication is undeniably integral in facilitating interpersonal relations. Similarly, the social marketing emphasises the social connection to exist between the sellers and the users prior to business transactions as good rapport aids the customers' purchase decisions. According to Öztamur and Karakadılar (2014), one notable value of social media marketing is its reachability thus making the attempt to raise the brand awareness among massive number of users is made swift and cost-effective. For instance, this is evident during the company's new campaign launchings as the spread shall generate better results or responses simply through the sharing of links' by the users on their preferred platforms. Therefore, such powerful online marketing strategy should definitely be part of today's business practices as an extension of marketing onslaught has been discussed, such as increase brand recognition, improve brand loyalty, reduced marketing costs and improve customer insight.

Shan, Song, and Ju (2016) found that many studies on small and medium-sized enterprises (SMEs) in Malaysia have been carried out. These studies are reportedly sharing a common research focus pertaining to the analysis of factors that contribute to the performance of SMEs, for example, the internalization and performance (Zehir, Köle, \& Yıldız, 2015), entrepreneurial orientation and performance (Shan et al., 2016), marketing capabilities and performance (Ejrami, Salehi, \& Ahmadian, 2016), and technology innovation and performance (Zolkepli \& Kamarulzaman, 2015). However, a study done by Parveen et al. (2016) showed even though social media has been widely recognised by Malaysian business, the social media marketing within the context of organisations is yet to manifest its impact thus calls forth the need to be widely discovered. For developing country like Malaysia, the impact of technologies such as social media is crucial to achieve the vision to be a developed nation and high-income status. In addition, the SME Master Plan (2012-2020) outlined that SMEs faced many challenges in using social media marketing in terms of information and communication technology (ICT) literacy, security matters and government initiatives. Thus, the present study seeks to address the gap by focusing on the mediating role of social media marketing between technological support, organisational support, government support and competitive intelligence on the performance of SMEs.

\section{Literature Review}

The gross domestic product (GDP) from services is reported to contribute the most to the growth of the national economy between 2005 and 2017, surpassing other sectors - construction, manufacturing, mining and quarrying (Malaysia, 2016). SMEs, therefore, become an integral sector to transform the economic environment of the country as Malaysia envisions to be a fully developed high-income nation by the year 2030. As the name suggests, SMEs are notably smaller in its operational size as opposed to big companies, yet Karimi and Naghibi (2015) reiterated the importance of SMEs to the growth of economy to be very considerable.

Performance is the key indicator of success of any businesses, either small or medium enterprises as well as large organisations. With regards to the performance of small businesses, their success is defined by the capability of these business makers to lead across multitude of aspects, such as the provision of opportunities for employment, the generation of wealth through business start-ups, their business longevity and lastly, business sustainability (Mamun,Muhammad \&Ismail, 2017; Zakaria, Yasoa', Ghazali, Ibrahim \& Ismail, 2017; Sandberg, Vinberg \& Pan, 2002). Meanwhile, Pfeffer and Salancik (2003) defined performance as the company's capability to initiate action and appropriate results, while Anggadwita and Mustafid (2014) defined organisational performance as the measure of a company's success in reaching its targets.

According to Kaplan and Norton (2007), analysing the performance of an organisation includes the consideration of both financial and non-financial aspects, following the primarily established business objectives. In this study, the researcher examines the non-financial performance which is also known as the organisational performance. The exclusion of financial performance in this study stemmed from the difficulties to obtain the financial data themselves, as these data are highly confidential thus its access is not granted to the unauthorised personnel. Therefore, according to Sapienza, Smith and Gannon (1988), this may lead to the owners/managers to potentially provide biased evaluations of their company's performance. In order to measure performance, the technological support must be given due importance (Soto-Acosta et al., 2016). 


\subsection{Technological Support}

Similarly, Soto-Acosta et al. (2016) elaborated that technological support entails the means which enable the organisations to deal with the environment i.e. organisations can adapt, control and change their surroundings in order to operate. This consists of the technological access made available through the gadgets like mobile phones, televisions, and computers; system installations like software or informatics; as well as electronic and mechanical equipment. This type of support has been regarded as an important factor for the companies to adopt technology in order to be competitive (Ismail, Razak, Yaacob, Zakaria, Amiruddin \& Luqman, 2016). Numerous researchers have explored the impact of technological support on innovation appropriation, and discovered both positive and negative outcomes. For example, Lehu (2007) highlighted the impact of compatibility on the reception of radio recurrence as proof of innovation in the South African retail sector. He contended that the radio-frequency identification (RFID) appropriation and execution are likely to be fruitful when the association develops an adaptable IT framework that will have the capacity to suit the RFID frameworks. On the contrary, the study by Gutierrez, Boukrami, \& Lumsden, (2015) discovered the irrelevance of technology in the calculation of reception in respect of the frameworks of big businesses. In a similar vein, Ahmad, Abu Bakar, Faziharudean, and Mohamad Zaki (2015) reported the adoption of technology among SMEs in Malaysia to be relatively low, despite its noteworthy benefits in boosting the business performance when embedded in the company's promotional strategies (Parveen et al., 2016). These contrasting views on technological support cautioned the uncertainty of outcomes following the analysis of business performance, yet it allows room for researchers to explore the impact of compatibility on social media adoption.

\subsection{Organisational Support}

Organisations are characterised as a solid, detectable relationship of persons occupied with aggregate exercises and seeking regular goals (Löfström, Örtenblad, \& Sheaff, 2015; Sheaff et al., 2003). According to Dahnil et al. (2014), organisational support is the measure of extent of beliefs that workers have towards their respective organisations with regards to how their contributions are valued, how their welfares are taken care of, and how their socio-emotional needs are fulfilled. Meanwhile, organisational support such as financial resources gauge the company's capital accessibility for creating and keeping up with the social media marketing venture. In particular, it alludes the expenses of site advancement, and additionally the whole upkeep, hosting, and operational capability that bolster capacities. On account of a small business, this variable is especially critical. Small organisations tend to not have the resources for IT investment (García-Moreno, García-Moreno, Nájera-Sánchez, \& De Pablos-Heredero, 2016). According to Ainin et al. (2015), the role of an organisation at present also encompasses the influence it has on the extent of reception and business performance, reflective of the social media marketing adopted. In the era of new technology, organisational support is pivotal as manifested through the encouragement and defense provided by the management in light of the data exchanges (Yusoff, Al Mamun, Ibrahim \& Hassan, 2018). The structural power of the top management preeminently controls the accessibility of assets which in turn, guarantees sufficient cash and time factor, alongside adequate human abilities - all of which are fundamental to initiate and fulfill new e-business ventures (Tarafdar \& Vaidya, 2006).

\subsection{Government Support}

The support from the government is integral as this influences the e-trade selection and distribution aspects, externally. This is due to the nature of the business operation in which its direction is navigated towards the external environment arena. Therefore, the survival of SMEs is predominantly dependent on the extent of controls and approaches coming from the governments. To illustrate, Baffour Awuah and Amal (2011) as well as Naudé et al., (2014) suggested that the proposed structure of incentives and taxes by the government on SMEs' imported merchandise to be a significant determinant of the business performance. Meanwhile, in the discussion of SMEs' internationalisation, Purcell and Toland (2004) advocated the government to facilitate SMEs at large through the establishment of a legalised framework which shall collectively and equally equip these business makers in their attempt to venture into the international marketplace. This is evident in the context of SMEs in India as Todd and Javalgi (2007) elicited that the Indian government went to a great length to aid their local organisations thus eventually enabled the accounts of SMEs in India to be empowered, upgraded, and enhanced, internationally. Nevertheless, the quintessential of a successful SMEs in Malaysia in view of this type of support is still debatable. This calls forth the concerted effort through government-support programmes to be made; for instance, financial and credit assistance, technical and training assistance, extension and advisory services, marketing and market research, as well as infrastructural support in order to smoothen the endeavours of local business makers. 


\subsection{TOE Framework}

Numerous theories on internet adoption are available, for example, Technology Acceptance Model (TAM), Unified Theory of Acceptance and Use of Technology (UTAUT), Diffusion of Innovation (DOI); and Technology, Organisational and Environment (TOE) framework. However, within the context of the organisational level, only DOI and TOE are applicable since TAM, UTAUT and Theory of Planned Behaviour (TPB) are all focusing on the individual level, with regards to the discussion of the adoption of technology.

In this study, TOE framework is applied. Accordingly, the process of adopting the social media marketing is evident in three-fold; technological, environmental and organisational. The TOE framework in particular, is very useful in studying the adoption of social media marketing. This framework emphasises the internal and external factors that influence a company's decision making phase - whether to adopt the social media marketing or not, due to the versatility of the application of the TOE framework itself.

Following the intention to adopt social media as part of their marketing strategy, SMEs have to understand the power of interactivity with their customers and its very implications which can be a double-edged sword. Past studies have found that the planning and usage of data frameworks consider the fruitful connection between humans and technology to be a key element (Lee \& Kozar, 2004; Shillair et al., 2015). In the studies by Parveen et al. (2016), they found that SMEs nowadays are increasingly using and adopting social media in their businesses in their attempt to boost the performance of their businesses. Nonetheless, the research conducted by Ahmad, Abu Bakar, Faziharudean, and Mohamad Zaki (2015) revealed otherwise. These authors reported the adoption of social media in business marketing in order to increase performance to be relatively slow. Based on the literature review and an analysis of empirical studies, the first hypothesis constructed for this study is:

H1: Social Media Marketing mediates the relationship between technological support and SME performance.

Previous researches have proven that the size of the company and the limitation of its financial resources to be the determinants in adopting social media marketing to improve the company's performance (Dholakia, 1995; Dholakia et al., 1993; Dholakia \& Kshetri, 2004). Additionally, the size of the firm is found to significantly influence the usage of e-commerce and its respective business performance (Intan Salwani, Marthandan, Daud Norzaidi \& Choy Chong, 2009). In a different study which has analysed the influence of support from the top management towards the performance of the firm, the organisational support is manifested through several variables, namely, the market orientation, the use of e-marketing, and the technological opportunism (Sheikh, Shahzad \& ku Ishak, 2017). Concurrently, Dahnil et al. (2014) further substantiated that the management of the companies directly influence the adoption of social media marketing. Based on the arguments and supports from those literatures, the following hypothesis was generated:

H2: Social Media Marketing mediates the relationship between organisational support and SME performance.

Meanwhile, the survival of SMEs following the adoption of social media as part of the marketing strategy is influenced by the government (Dahnil et al., 2014; Hanafizadeh et al., 2012). Several forms of assistance from the government to enhancing SMEs' performance have been suggested by Hanafizadeh et al. (2012), one of them is through the development of a legal system. For instance, in Malaysia, the tax deduction is an example of such measure taken to aid the SMEs (Hashim, Mahajar, \& Ahmad, 2003). Additionally, the Malaysian government has increasingly launched programmes over the years, both at the federal and state levels (Ismail and Othman, 2014). Taking the form of giving "assistance" to the SMEs, these businesses are not only being supported financially, technically and infrastructural wise, but they also received guidance on marketing and market research. Other services provided include facilitating SMEs through advisory and extension prospects. Therefore, these shall increase the likelihood of the SMEs to adopt social media marketing. The review of literatures and the analysis of empirical studies led to the third hypothesis to be constructed:

H3: Social Media Marketing mediates the relationship between government support and SME performance.

\subsection{Competitive Intelligence}

All companies usually exhibit various methods of collecting information on their competitors and the external business environment in order to find new markets and increase revenue. However, there is an absence of a proper procedure to transfer this useful information into knowledge and intelligence that can be valuable to formulate competitive strategies. Competitive intelligence is therefore developed as a tool for competitiveness since it is a systematic, ethical and continuous process which involves information on external environment that has the capacity to affect the competitive position of a company or country (Sewdass \& Du Toit, 2014). 
The view of Bose (2008) towards how competitive intelligence enhances the company's trajectory has further emphasised its necessity since such intelligence enables the investigation of the competitive environment. This concurs with Vuori's (2011) tenet pertaining to the employment of competitive intelligence in aiding the company's strategic decision making phase through the defining, gathering, analysing and distributing of intelligence stages which are applicable across all plausible conditions in the company itself. Apart from the foregoing tactical advantage, succinct studies alluded competitive intelligence to also be evident in areas like knowledge management (Jaharuddin, Mohamed, \& Sambasivan, 2015) and supply chain (Jaharuddin, Dato' Mansor, \& Yaakob, 2016). Meanwhile, Štefániková and Masárová (2014) proposed the conduct of surveys as a method to utilise competitive intelligence in identifying both strengths and weaknesses of potential competitors, as well as recognising their respective strategic objectives. Concurrently, the monitoring and evaluating processes of the said companies or organisations also take place. Based on the data collection carried out via competitive intelligence, its analysis and synthesis of information shall then be transformed into strategic knowledge accordingly. Meanwhile, the supplemental data on the competitors as well as other entities (e.g. law and legislation; demographic, market, and political contexts) in the corporate environment are available for monitoring. However, within the context of SMEs in Malaysia, the scantiness of research on this particular aspect of non-financial performance is remarkable despite the ability of competitive intelligence to lay a strong foundation in terms of the strategic management in local business practices (Mohsin, Halim, \& Ahmad, 2015). Additionally, the authors reiterated such scarcity to also hinder the prospects for SMEs' improvements, thus affecting their overall business performance.

\subsection{RBV Theory}

This present study also utilised Barney's (1991) Resource-Based View (RBV) which was developed from Penrose's (1959) Theory of the Growth of the Company in the attempt to identify the company's potential key resources. Penrose (1959), who first suggested the concept of the RBV, stated the internal characteristics of the company determine the sustainability of growth accordingly. The RBV of a company gives an indication that the company attains a sustainable competitive advantage when it has succeeded to manage its assets in such a way that the results cannot be duplicated by competitors (Hooley et al., 2005). RBV literature suggests that the competitive intelligence which consists of distinctive disciplinary expertise, shall prevent potential imitations through involving a unique process which contribute to a company's overall competitive advantage (Hughes, 2005).

Essentially, previous authors i.e. Fan and Gordon (2014); Hawking and Sellitto (2015) have noted the influential role of competitive intelligence as it had positively facilitated company's decision making process through enabling the top management to be well informed. In addition, Vuori (2011) also alluded a remarkably improved social media marketing within a company to benefit from a properly distributed competitive intelligence and vice versa. Nevertheless, as much as competitive intelligence is seemingly an area worthy of garnering interests, Bernhardt (1996) gave the academicians and practitioners the benefit of the doubt with regards to proving the capability of such intelligence to be of significant support in enhancing the performance of business. Hence, Gbosbal and Kim (1986) suggested the intelligence unit to play a pivotal role by being involved in the business directly in ensuring the validity of the performance. Based on the empirical studies and justification on competitive intelligence, the following hypothesis was developed:

H4: Social Media Marketing mediates the relationship between competitive intelligence and SME performance.

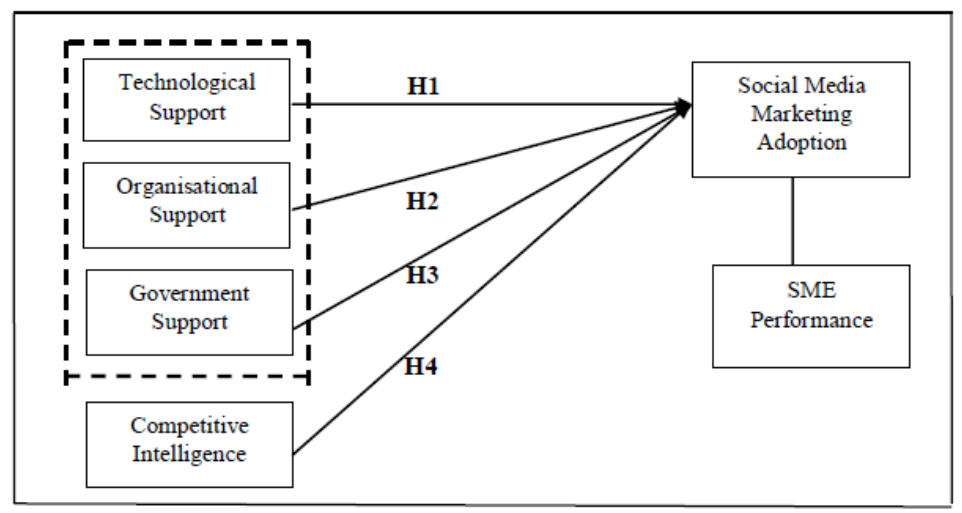

Figure 1. Proposed research framework 


\section{Methodology}

The empirical data for this study were obtained through the distribution of self-administered questionnaire to the respondents in the east coast region of Peninsular Malaysia. The first underlying reason that led to the selection of these three states - Pahang, Kelantan, and Terengganu as the locations of this study is due them being geographically and economically homogenous. Secondly, they are targeted to grow into a cumulatively developed region in 2020 which concurs with Council's (2008) suggestion which stated that the country's economic development is different from state to state and region to region. The collection of the data included 1920 samples out of 89,779 SMEs in the east coast region, in order to get 384 respondents following Krejcie and Morgan's (1970) table. Out of that number, 339 completed questionnaires were returned after the follow-up sessions had been made within 6 months, making the response rate at 21.1 percent.

This study applied the SmartPLS Version 3 in order to assess both the measurement and structural models. With regards to the first (measurement) model, Average Variance Extracted (AVE) was used to observe the convergent validity. Additionally, composite reliability (CR) was assessed by using Cronbach's Alpha value. On the other hand, the second (structural) model runs the relationship between the latent variables in the research model. According to Hair et al. (2014), the three criteria which enabled this assessment include (i) the coefficient of determination (R2), (ii) the cross validated redundancy $(\mathrm{Q} 2)$, as well as the path coefficients.

In assessing the company profiles, descriptive statistics was used. The researchers primarily outlined seven categories for this assessment, namely, (i) type of industry, (ii) location of business, (iii) types of company ownership, (iv) age of business, (v) number of full-time employees, (vi) type of company's Internet connection, and (vii) years of Internet usage for business purposes.

The breakdown for the first category is as follows - service, 46.6\%; manufacturing, $42.5 \%$; others, $10.9 \%$. Meanwhile, the breakdown for the second category is as follows - total respondents from Kelantan, $39.8 \%$; total respondents from Terengganu, 38.3\%; total respondents from Pahang, 21.8\%. Next, the breakdown for the third category is as follows - sole proprietor, $75.2 \%$; partnership, $17.7 \%$; limited company, $7.1 \%$. Besides, the breakdown for the fourth category is as follows -4 to 8 years, $38.3 \%$; 9 to 15 years, $28.3 \%$; 16 to 20 years, $5.0 \%$; less than 3 years, 24.4\%; above 20 years, $3.8 \%$. Subsequently, the breakdown for the fifth category is as follows - less than 5 employees, $49.3 \%$; 5 to 50 employees, $44.0 \%$; 51 to 150 employees, $6.2 \%$; 150 to 200 employees, $0.6 \%$. Apart from that, the breakdown for the sixth category is as follows - Jaring, 31.0\%; Streamyx, 30.7\%; TMNet, 24.8\%; Leased Line, $0.3 \%$. Lastly, the breakdown for the seventh category is as follows - less than 5 years, $82.6 \%$; 6 to 10 years, $15.0 \%$; 11 to 15 years, $1.8 \%$; more than 20 years, $0.6 \%$.

\subsection{Measurement Scales}

This study utilised the 5-point Likert scale which ranges from strongly disagree to strongly agree. In order to measure the first construct i.e. technological support, nine (9) items were included (adapted from Ainin et al., 2015). Based on the suggestions, the questions were made to consist of aspects pertaining to compatibility, cost effectiveness, and interactivity. Modification was done to the original questions due to the comments and feedback received from the pre-test. Besides, the respondents suggested the ungrouping of all items in order to fit into this particular study as well as to prevent confusion regarding the details of the questions. Next, the second construct i.e. organisational support was measured using six (6) items as proposed by Chong and Chan (2012) who suggested the organisational support to comprise of financial resources and company sizes. However, the previously ungrouped items were then regrouped into one element, thus forming the sole organisational support. Meanwhile, five (5) items which were adapted from Tan and Teo (2000) as well as Kapurubandara and Lawson (2009) made up the third construct i.e. government support. With regards to this construct, the respondents were asked on the financial assistance and the infrastructure provided in the adoption of social media as the tools for their marketing strategy. For the fourth construct i.e. competitive intelligence, five (5) items were adapted from Vuori (2011) while the following five (5) questions from Zolkepli and Kamarulzaman (2015) were also adapted in order to measure the adoption of social media marketing variable. Lastly, the performance of the companies construct was evaluated based on the observations of the owners/managers who responded to the questionnaire adapted from Maurya et al. (2015). The authors suggested the inclusion of aspects like the customer satisfaction, the customer value, the likelihood of attracting new customer, the market value as well as growth, in order to measure the business performance. 


\section{Finding and Discussion}

Normality is described by a bell-shaped curve that is symmetrical, where the middle part shows the greatest frequency of scores while smaller frequencies are found towards the extremes (Pallant, 2013). The results of the normality test are presented in Table 1. According to George and Mallery (2016), the skewness and kurtosis values that are acceptable should be ranged between -1 to +2 . From the results, it can be deduced that the data is normally distributed.

Table 1. Descriptive statistics

\begin{tabular}{lcccccc}
\hline & Mean & Std. Deviation & \multicolumn{2}{c}{ Skewness } & \multicolumn{2}{c}{ Kurtosis } \\
& Statistic & Statistic & Statistic & Std. Error & Statistic & Std. Error \\
\hline Technological Support & 4.0203 & .71045 & -.907 & .132 & 1.711 & .264 \\
Organisational Support & 3.2940 & .71641 & .077 & .132 & .113 & .264 \\
Government Support & 3.7280 & .78402 & -.767 & .132 & .924 & .264 \\
Competitive Intelligence & 3.6212 & .72912 & -.681 & .132 & 1.038 & .264 \\
Social Media Marketing Adoption & 3.9304 & .77007 & -.576 & .132 & .498 & .264 \\
SME Performance & 3.8761 & .76100 & -.810 & .132 & 1.220 & .264 \\
\hline
\end{tabular}

Hair et al. (2010) explained that outliers are present following the selections made by the respondents which leaned towards the extremes, as they observed the arrangement of values throughout the variables. In this study, there were thirty-six (36) variables and any individual variable with a Mahalanobis Distance score (D2) greater than $(\chi 2)=$ 67.99 is regarded as a multivariate outlier thus can be excluded from the analysis. For this study, no case reported any presence of outlier.

High correlations among the variables led to the occurrence of multicollinearity. Hence, the Variance Inflated Factor (VIF) is one of the ways to examine multicollinearity. Hair et al. (2010) elaborated that multicollinearity exists when the value of VIF exceeds 10 and the tolerance value which is lower than .10. Based on Table 2 below, the value of tolerance is greater than 0.6 and VIF score is less than 10. Hence, it can be deduced that multicollinearity is nonexistent.

Table 2. Tolerance and VIF value

\begin{tabular}{lccccccc}
\hline & \multicolumn{2}{c}{$\begin{array}{c}\text { Unstandardized } \\
\text { Coefficients }\end{array}$} & \multicolumn{2}{c}{$\begin{array}{c}\text { Standardized } \\
\text { Coefficients }\end{array}$} & \multicolumn{3}{c}{$\begin{array}{c}\text { Collinearity } \\
\text { Statistics }\end{array}$} \\
& $\mathrm{B}$ & Std. Error & Beta & t & Sig. & Tolerance & VIF \\
\hline (Constant) & 0.384 & 0.195 & & 1.970 & 0.050 & & \\
Technological Support & 0.241 & 0.050 & 0.225 & 4.780 & 0.000 & 0.655 & 1.526 \\
Organisational Support & 0.126 & 0.049 & 0.119 & 2.600 & 0.010 & 0.695 & 1.439 \\
Government Support & 0.202 & 0.047 & 0.208 & 4.286 & 0.000 & 0.617 & 1.620 \\
Competitive Intelligence & 0.374 & 0.051 & 0.358 & 7.337 & 0.000 & 0.610 & 1.640 \\
\hline
\end{tabular}

a. Dependent Variable: SME Performance

\subsection{Measurement Model}

Table 3 outlined the testing of construct validity, composite reliability and Average Variance Extracted (AVE) for the first phase of measurement model. Sekaran and Bougie (2010) posited that the construct validity demonstrates whether the results obtained are a good fit for the theories that the test is designed for. Accordingly, the value should be higher than 0.7 (Hair et al., 2011; Valérie, 2012). Based on this table, no item was deleted because all of the items were more than 0.70 . Next, the Cronbach's alpha coefficient was acquired along the composite reliability values in order to analyse the inter-item consistency of the measurement items. According to Hair et al. (2011) and Valérie (2012), the Cronbach's alpha should have a value of more than 0.7. The results showed that all values of composite reliability ranged from 0.929 to 0.962 which denote that the values exceeded the recommended value. With reference 
to AVE, measures of the variance obtained by the indicators after allowing measurement error should be greater than 0.50, so that the use of the construct is justified (Hair et al., 2011; Valérie, 2012). For this study, the AVEs were all within the suggested range which falls between 0.685 and 0.808 .

Table 3. Measurement model result

\begin{tabular}{|c|c|c|c|c|}
\hline Construct & Items & Loadings & $\mathrm{CR}$ & AVE \\
\hline \multirow[t]{9}{*}{ Technological Support } & SA1 & 0.798 & 0.954 & 0.699 \\
\hline & SA2 & 0.825 & & \\
\hline & SA3 & 0.846 & & \\
\hline & SA4 & 0.857 & & \\
\hline & SA5 & 0.855 & & \\
\hline & SA6 & 0.859 & & \\
\hline & SA7 & 0.867 & & \\
\hline & SA8 & 0.863 & & \\
\hline & SA9 & 0.744 & & \\
\hline \multirow[t]{6}{*}{ Organisational Support } & SB1 & 0.791 & 0.929 & 0.685 \\
\hline & SB2 & 0.821 & & \\
\hline & SB3 & 0.824 & & \\
\hline & SB4 & 0.856 & & \\
\hline & SB5 & 0.846 & & \\
\hline & SB6 & 0.826 & & \\
\hline \multirow[t]{5}{*}{ Government Support } & $\mathrm{SC} 1$ & 0.851 & 0.944 & 0.771 \\
\hline & $\mathrm{SC} 2$ & 0.896 & & \\
\hline & SC3 & 0.894 & & \\
\hline & $\mathrm{SC} 4$ & 0.841 & & \\
\hline & SC5 & 0.906 & & \\
\hline \multirow{5}{*}{$\begin{array}{l}\text { Competitive } \\
\text { Intelligence }\end{array}$} & SD1 & 0.867 & 0.954 & 0.806 \\
\hline & $\mathrm{SD} 2$ & 0.907 & & \\
\hline & SD3 & 0.886 & & \\
\hline & SD4 & 0.907 & & \\
\hline & SD5 & 0.922 & & \\
\hline \multirow{5}{*}{$\begin{array}{l}\text { Social Media } \\
\text { Marketing Adoption }\end{array}$} & SE1 & 0.911 & 0.952 & 0.800 \\
\hline & SE2 & 0.913 & & \\
\hline & SE3 & 0.879 & & \\
\hline & SE4 & 0.848 & & \\
\hline & SE5 & 0.884 & & \\
\hline \multirow[t]{6}{*}{ SME Performance } & SF1 & 0.904 & 0.962 & 0.808 \\
\hline & $\mathrm{SF} 2$ & 0.896 & & \\
\hline & SF3 & 0.906 & & \\
\hline & SF4 & 0.893 & & \\
\hline & SF5 & 0.907 & & \\
\hline & SF6 & 0.888 & & \\
\hline
\end{tabular}

$\mathrm{CR}=$ Composite Reliability, $\mathrm{AVE}=$ Average Variance Extracted, $\mathrm{CA}=$ Cronbach's Alpha 
For the second phase of measurement model, the discriminant validity was obtained. Henseler, Ringle, and Sarstedt (2015) suggested the heterotrait-monotrait (HTMT) to be performed in order to measure the discriminant validity. Assigning HTMT as a criterion requires its comparison to be carried out against a predefined threshold. The existing literatures suggested a threshold value of 0.85 (Clark and Watson, 1995; Kline, 2011) while Voorhees, Brady, Calantone, and Ramirez (2016) proposed that a threshold value of 0.90 can claim the absence of discriminant validity. Hence, the result presented in Table 4 showed that the discriminant validity has already fulfilled the threshold.

Table 4. Heterotrait-Monotrait ratio

\begin{tabular}{lccccc}
\hline & CI & GS & OS & SMEP & SMM \\
\hline Government Support (GS) & 0.504 & & & & \\
Organisational Support (OS) & 0.459 & 0.557 & & & \\
SME Performance (SMEP) & 0.665 & 0.574 & 0.479 & & \\
Social Media Marketing Adoption & 0.625 & 0.491 & 0.471 & 0.667 & \\
(SMM) & 0.576 & 0.485 & 0.326 & 0.580 & 0.466 \\
Technological Support (TS) & & & &
\end{tabular}

\subsection{Assessment of Predictive Relevance}

In order to generate cross validated communality and cross validated redundancy, the value of R2 and effect sizes can be used to evaluate the quality of the structural model by employing blindfolding procedure. Hair et al. (2011) stated that endogenous latent variables with $\mathrm{R} 2$ values of $0.75,0.50$ or 0.25 can be described as substantial, moderate or weak, respectively.

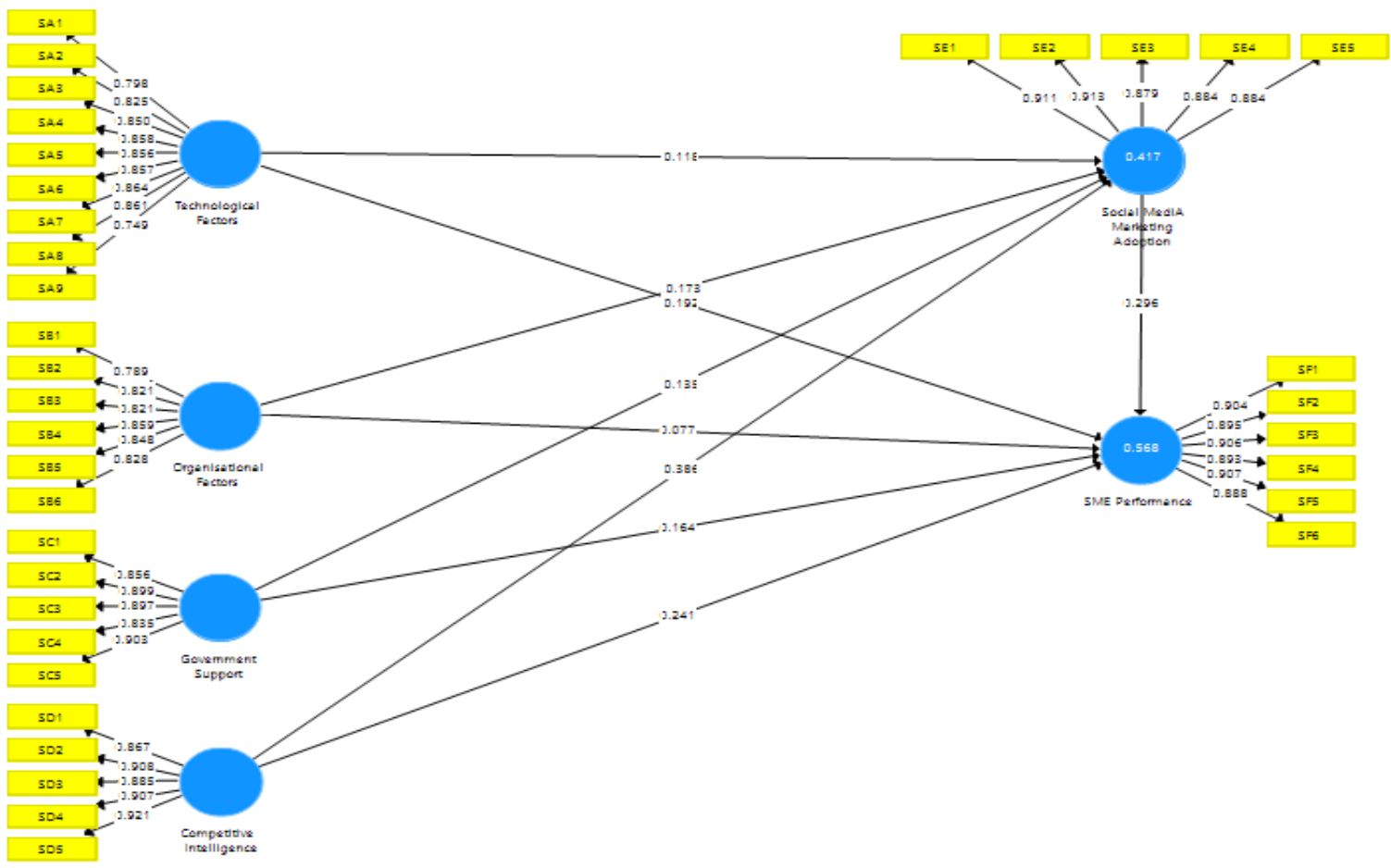

Figure 2. Result of path analysis

As shown in Figure 2, the R2 value was 0.417 - this suggests that technological support, organisational support, government support and competitive intelligence can account for 41.7 percent of the variance in social media marketing adoption, thus represent a moderate range. Then, the R2 of SME performance was 0.562 , indicating that 
technological support, organisational support, government support, competitive intelligence and social media marketing adoption can account for 56.2 percent of the variance in performance.

The predictive relevance $(\mathrm{Q} 2)$ is another measure for the evaluation of the structural model in which it demonstrates how well the observed values are rebuilt by the model and its parameter estimates (Chin, 2010; Hair et al., 2011). Ringle et al. (2005) suggested Q2 values to be obtained using the blindfolding technique. In Table 5, the obtained cross validated redundancy values for SME performance and social media marketing adoption were found to be 0.426 and 0.308 , respectively. Thus, this supports the proposition that the model has sufficient prediction quality.

Table 5. Predictive relevance of the model

\begin{tabular}{lccc}
\hline & SSO & SSE & Q $^{2}(=1-\mathrm{SSE} / \mathrm{SSO})$ \\
\hline SME Performance & $2,034.000$ & $1,167.289$ & 0.426 \\
Social Media Marketing Adoption & $1,695.000$ & $1,172.529$ & 0.308 \\
\hline
\end{tabular}

\subsection{Assessment of Structural Model}

Once the measurement model is examined, the testing of the structural model is carried out via the analysis of the inner model. For this study, the hypotheses were tested using the PLS approach by assessing the path coefficient $(\beta)$ through structural equation modelling as presented in Table 6.

Table 6. Indirect path analysis

\begin{tabular}{llllcccccl}
\hline Hypothesis & IV & Mediation & DV & beta & t value & p-values & LL & UL & Result \\
\hline H1 & TF & SMM & SMEP & 0.035 & 2.107 & $0.036^{*}$ & 0.010 & 0.062 & Supported \\
H2 & OF & SMM & SMEP & 0.051 & 2.695 & $0.007^{*}$ & 0.026 & 0.090 & Supported \\
H3 & GS & SMM & SMEP & 0.040 & 2.163 & $0.031^{*}$ & 0.016 & 0.076 & Supported \\
H4 & CI & SMM & SMEP & 0.114 & 4.197 & $0.001^{*}$ & 0.077 & 0.167 & Supported \\
\hline
\end{tabular}

*Significant at $\mathrm{p}<0.05$. IV=Independent Variable, $\mathrm{DV}=$ Dependent Variable, $\mathrm{TF}=$ Technological support, $\mathrm{GS}=$ Government support, $\mathrm{CI}=$ Competitive intelligence, $\mathrm{SMM}=$ Social Media Marketing Adoption, SMEP=SME Performance

A bootstrapping analysis was run to investigate the mediating effect of the adoption of social media marketing on the relationship between independent variables and the performance of SME. Firstly, the analysis revealed the indirect effect $\beta=0.035$ to be significant with the $\mathrm{t}$-values $=2.107$. Also, the 95 percent Bootstrap Confidence Interval (CI) (Preacher \& Hayes, 2008) does not straddle zero in between [LL $=0.010, \mathrm{UL}=0.062]$ which indicates the social media marketing to mediate the relationship between technological support and the performance of SME. Therefore, the mediation effect can be deduced to be statistically significant. Thus, H1 is supported.

Next, the findings revealed how the adoption of social media marketing played the mediating role between organisational support and the performance of SME $(\beta=0.051, t$-values=2.695). This result is also supported by the values of Bootstrap CI: $[\mathrm{LL}=0.026, \mathrm{UL}=0.090]$ which does not straddle zero in between which suggests that the adoption of social media marketing is a mediator between technological support and the performance of SME. Therefore, the mediation effect can be deduced to be statistically significant. Hence, $\mathrm{H} 2$ is supported.

Thirdly, the bootstrapping analysis revealed that the indirect effect $\beta=0.040$ was significant with the $t$-values=2.163. Also, the 95 percent Bootstrap Confidence Interval (CI) (Preacher \& Hayes, 2008) does not straddle zero in between $[\mathrm{LL}=0.016, \mathrm{UL}=0.076]$ which indicates the social media marketing to mediate the relationship between government support and the performance of SME. Therefore, the mediation effect can be deduced to be statistically significant. Thus, $\mathrm{H} 3$ is supported.

Finally, the finding revealed how the adoption of social media marketing played the mediating role between competitive intelligence and the performance of $\operatorname{SME~}(\beta=0.114$, $t$-values $=4.197)$. This result is also supported with the values of Bootstrap CI: $[\mathrm{LL}=0.077, \mathrm{UL}=0.167]$ which does not straddle a zero in between indicating that the 
adoption of social media marketing is a mediator between competitive intelligence and the performance of SME. Therefore, the mediation effect can be deduced to be statistically significant. Hence, H4 is supported.

\section{Conclusion and Recommendation}

The present study shows the mediating role of the adoption of social media marketing between five constructs, namely, the technological support, the organisational support, the government support, the competitive intelligence, as well as the performance of SME. In order to successfully position the business in the marketplace, the company requires a sound strategic orchestration due to the difficulties to attain an established status in today's competitive global environment. Moreover, the absence of these supports i.e. technological, organisational, government, competitive intelligence shall harm the businesses following the deficiency of information on emerging opportunities as well as threats thus restrict the discovery of technological innovation such as the social media marketing (Aboelmaged, 2014; Zhu et al., 2006).

This also suggests that the aforementioned supports are indeed very critical towards the strategic formulation of the organisations for the future course of action, in order for the company to implement social media marketing as part of their business strategies. Hence, the findings provide an evidence that the process of social media marketing adoption through systematic technological support, organisational support, government support and competitive intelligence as a source for the SME to enhance their performance. These findings are also in line with previous study by Trainor (2012) who claimed that social media marketing can lead to superior performance. Zhou, Wu, and Luo (2007) also found in their studies that the performance of business is significantly influenced by knowledge, learning and trust through social media marketing.

Theoretically, other authors make use of the TOE framework alongside other theories in order to understand the adoption of IT such as TOE with DOI (Sin Tan et al., 2009; Thong, 1999; Wang et al., 2010), TOE with institutional theory (Gibbs \& Kraemer, 2004; Soares-Aguiar \& Palma-dos-Reis, 2008) and TOE with Iacovou et al. (1995) model (Chiu et al., 2006; Oliveira \& Martins, 2010). However, there are much fewer studies which combined the TOE framework with RBV theory. In this study, RBV theory represented the relationship between TOE framework and competitive intelligence towards SME performance. TOE framework has been measured by using technological support, organisational support and government support.

Practically, the results of this research will be valuable to a number of organisations, including the existing SMEs and business owners. A study done by Parveen et al. (2016) shows Malaysia is one of the eight largest communities that utilise social media extensively. Nonetheless, the manifestation of the impact of the social media marketing on organisational performance is still scarce. SME owners/managers must be receptive towards the significance of technological support as well as competitive intelligence in the enhancement of their business performance. The findings of this study would also be important to the policy makers such as SME Corp or other relevant government agencies in designing future programmes for the SME sector in the country. Similarly, the Malaysian government needs to play their role in helping SMEs to be innovative in utilising social media as a marketing tool extensively by providing training programmes on how to maximise the use of social media marketing in their businesses. Other than that, the local government or any relevant agencies such as Malaysia Communications and Multimedia Commission (MCMC) and Malaysia Digital Economy Corporation (MDEC) should administer technical workshop and training on how to operate any functions supported by social media, especially in East Coast Region. The SME owners from this region in particular, have reported the lack of training and workshop on how to extensively use social media with regards to marketing their businesses.

\section{References}

Aboelmaged, M. G. (2014). Predicting e-readiness at firm-level: An analysis of technological, organizational and environmental (TOE) effects on e-maintenance readiness in manufacturing firms. International Journal of Information Management, 34(5), 639-651.

Ahmad, S. Z., Bakar, A. R. A., \& Ahmad, N. (2019). Social media adoption and its impact on firm performance: the case of the UAE. International Journal of Entrepreneurial Behavior \& Research.

Ainin, S., Parveen, F., Moghavvemi, S., Jaafar, N. I., \& Mohd Shuib, N. L. (2015). Factors influencing the use of social media by SMEs and its performance outcomes. Industrial Management \& Data Systems, 115(3), 570-588.

Anggadwita, G., \& Mustafid, Q. Y. (2014). Identification of factors influencing the performance of small medium enterprises (SMEs). Procedia-Social and Behavioral Sciences, 115, 415-423. 
Bianchi, C., \& Andrews, L. (2015). Investigating marketing managers' perspectives on social media in Chile. Journal of Business Research, 68(12), 2552-2559.

Bose, R. (2008). Competitive intelligence process and tools for intelligence analysis. Industrial Management \& Data Systems, 108(4), 510-528.

Dahnil, M. I., Marzuki, K. M., Langgat, J., \& Fabeil, N. F. (2014). Factors influencing SMEs adoption of social media marketing. Procedia-Social and Behavioral Sciences, 148, 119-126.

Dholakia, R. R., \& Kshetri, N. (2004). Factors impacting the adoption of the Internet among SMEs. Small Business Economics, 23(4), 311-322.

du Toit, A. S. (2003). Competitive intelligence in the knowledge economy: what is in it for South African manufacturing enterprises?. International Journal of Information Management, 23(2), 111-120.

Ejrami, M., Salehi, N., \& Ahmadian, S. (2016). The effect of marketing capabilities on competitive advantage and performance with moderating role of risk management in importation companies. Procedia Economics and Finance, 36(16), 22-28.

García-Moreno, M. B., García-Moreno, S., Nájera-Sánchez, J. J., \& De Pablos-Heredero, C. (2016). An explanatory model of the organizational factors that explain the adoption of E-business. Journal of Industrial Engineering and Management, 9(2), 547.

George, D., \& Mallery, P. (2016). IBM SPSS Statistics 23 step by step: A simple guide and reference. Routledge.

Grahl, T. (2016). The 6 Types of Social Media. Timgrahl.com. Retrieved 28 Jan. 2016, from http://timgrahl.com/the-6-types-of-social-media/

Gutierrez, A., Boukrami, E., \& Lumsden, R. (2015). Technological, Organisational and Environmental factors influencing managers' decision to adopt cloud computing in the UK. Journal of Enterprise Information Management, 28(6), 788-807.

Hair, J. F., \& Ringle, S. (2011). PLS-SEM: Indeed a silver bullet. Journal of Marketing Theory and Practice, 19(2), 139-152.

Hair, J. F., Anderson, R., \&Babin, B. (2010). Multivariate data analysis: A global perspective (Vol. 7). Pearson Upper Saddle River, NJ.

Hanafizadeh, P., Behboudi, M., Ahadi, F., \& Ghaderi Varkani, F. (2012). Internet advertising adoption: a structural equation model for Iranian SMEs. Internet Research, 22(4), 499-526.

Hashim, M., Mahajar, A., \& Ahmad, S. (2003). Innovative practices of Malaysian firms: Some evidence from Enterprise 50 winners. Malaysian Management Review, 38(2), 19-27.

Henseler, J., Ringle, C. M., \& Sarstedt, M. (2015). A new criterion for assessing discriminant validity in variance-based structural equation modeling. Journal of the Academy of Marketing Science, 43(1), 115-135.

Hooley, G. J., Greenley, G. E., Cadogan, J. W., \& Fahy, J. (2005). The performance impact of marketing resources. Journal of Business Research, 58(1), 18-27.

Hughes, S. (2005). Competitive intelligence as competitive advantage. Journal of Competitive Intelligence and Management, 3(3), 3-18.

Ismail, M., Razak, R. C., Yaacob, M. R., Zakaria, M. N., Amiruddin, N. H., \& Luqman, A. (2016). Predictive modelling of mobile marketing usage among generation Y: A preliminary survey. International Journal of Interactive Mobile Technologies, 10(2), 49-57.

Jaharuddin, N. S., Dato'Mansor, Z., \& Yaakob, S. (2016). Assessing the Supply Chain Intelligence Practices of Small Medium Enterprises in Malaysia. Procedia Economics and Finance, 35, 515-521.

Jaharuddin, N. S., Mohamed, Z. A., \& Sambasivan, M. (2015). Supply Chain Intelligence in Business Organisations: A Malaysian Perspective. Pertanika Journal of Social Sciences \& Humanities, 23.

Kaplan, A. M., \& Haenlein, M. (2010). Users of the world, unite! The challenges and opportunities of Social Media. Business Horizons, 53(1), 59-68.

Kapurubandara, M., \& Lawson, R. (2009). E-commerce adoption and appropriation by SMEs in Sri Lanka. Emerging Markets and E-Commerce in Developing Economies, IGI Global, 105-107.

Karimi, S., \& Naghibi, H. S. (2015). Social Media Marketing (SMM) Strategies for Small To Medium Enterprises 
(SMES). International Journal of Information, Business and Management, 7(4), 86.

Kline, R. B. (2011). Convergence of structural equation modeling and multilevel modeling. na.

Krejcie, R. V., \& Morgan, D. W. (1970). Determining sample size for research activities. Educational and Psychological Measurement, 30(3), 607-610.

Lehu, J.-M. (2007). Branded entertainment: Product placement \& brand strategy in the entertainment business. Kogan Page Publishers.

Malaysia, S. C. (2016). Profile and Importance to the Economy. Retrieved from http://www.smecorp.gov.my/index.php/en/policies/2015-12-21-09-09-49/profile-and-importance-to-the-economy

Mamun, A. A., Muhammad, N. M. N., \& Ismail, M. (2017). Absorptive Capacity, Innovativeness and the Performance of Micro-enterprises in Malaysia. Vison, 21(3), 243-249.

Maurya, U. K., Mishra, P., Anand, S., \& Kumar, N. (2015). Corporate identity, customer orientation and performance of SMEs: Exploring the linkages. IIMB Management Review, 27(3), 159-174.

Mohsin, A. A., Halim, H. A., \& Ahmad, N. H. (2015). Competitive intelligence among SMEs: assessing the role of entrepreneurial attitude orientation on innovation performance. Innovation, Finance, and the Economy (pp. 15-22). Springer.

Naudé, P., Zaefarian, G., Tavani, Z. N., Neghabi, S., \& Zaefarian, R. (2014). The influence of network effects on SME performance. Industrial Marketing Management, 43(4), 630-641.

Öztamur, D., \& Karakadilar, İ. S. (2014). Exploring the role of social media for SMEs: as a new marketing strategy tool for the firm performance perspective. Procedia-Social and behavioral sciences, 150, 511-520.

Parveen, F., Jaafar, N. I., \& Ainin, S. (2015). Social media usage and organizational performance: Reflections of Malaysian social media managers. Telematics and Informatics, 32(1), 67-78.

Penrose, E. T. (1959). Profit sharing between producing countries and oil companies in the Middle East. The Economic Journal, 69(274), 238-254.

Preacher, K. J., \& Hayes, A. F. (2008). Asymptotic and resampling strategies for assessing and comparing indirect effects in multiple mediator models. Behavior research methods, 40(3), 879-891.

Purcell, F., \& Toland, J. (2004). Electronic commerce for the South Pacific: A review of e-readiness. Electronic Commerce Research, 4(3), 241-262.

Ricciardelli, L. A., Nackerud, L., Quinn, A. E., Sewell, M., \& Casiano, B. (2020). Social media use, attitudes, and knowledge among social work students: Ethical implications for the social work profession. Social Sciences \& Humanities Open, 2(1), 100008.

Ringle, C. M., Wende, S., \& Will, A. (2005). SmartPLS 2.0 (beta). Hamburg.

Samat, M. F., Hashim, H., \& Yusoff, R. N. R. (2014). Endorser credibility and its influence on the attitude toward social media advertisement in Malaysia. Review of Integrative Business \& Economics, 4(1), 144-159.

Sandberg, K. W., Vinberg, S., \& Pan, Y. (2002). 45 Integrating working. Engineering Psychology and Cognitive Ergonomics: Industrial economics, HCI, and applied cognitive psychology, 6, 357.

Sekaran, U., \& Bougie, R. (2010). Research methods for business: A skill building approach. Research methods for business: A skill building approach. Wiley.

Sewdass, N., \& Du Toit, A. (2014). Current state of competitive intelligence in South Africa. International Journal of Information Management, 34(2), 185-190.

Shan, P., Song, M., \& Ju, X. (2016). Entrepreneurial orientation and performance: Is innovation speed a missing link?. Journal of Business Research, 69(2), 683-690.

Sheikh, A. A., Shahzad, A., \& ku Ishak, A. (2017). The Impact of Market Orientation, Top Management Support, Use of E-Marketing and Technological Opportunism on the Firm Performance: A Mediated-Moderation and Moderated-Mediation Analysis. Abasyn University Journal of Social Sciences, 10(2).

Shillair, R., Cotten, S. R., Tsai, H.-Y. S., Alhabash, S., LaRose, R., \& Rifon, N. J. (2015). Online safety begins with you and me: Convincing Internet users to protect themselves. Computers in Human Behavior, 48, 199-207.

Soto-Acosta, P., Popa, S., \& Palacios-Marqués, D. (2016). E-business, organizational innovation and firm 
performance in manufacturing SMEs: an empirical study in Spain. Technological and Economic Development of Economy, 22(6), 885-904.

Tan, M., \& Teo, T. S. (2000). Factors influencing the adoption of Internet banking. Journal of the AIS, I(1es), 5.

Tarafdar, M., \& Vaidya, S. D. (2006). Challenges in the adoption of E-Commerce technologies in India: The role of organizational factors. International Journal of Information Management, 26(6), 428-441.

Todd, P. R., \& Javalgi, R. R. G. (2007). Internationalization of SMEs in India: Fostering entrepreneurship by leveraging information technology. International Journal of Emerging Markets, 2(2), 166-180.

Trainor, K. J. (2012). Relating social media technologies to performance: A capabilities-based perspective. Journal of Personal Selling \& Sales Management, 32(3), 317-331.

Valérie, F. (2012). (Re) discovering the PLS approach in management science. Management, 15(1).

Voorhees, C. M., Brady, M. K., Calantone, R., \& Ramirez, E. (2016). Discriminant validity testing in marketing: an analysis, causes for concern, and proposed remedies. Journal of the Academy of Marketing Science, 44(1), 119-134.

Vuori, V. (2011). Social media changing the competitive intelligence process: Elicitation of employees' competitive knowledge. Tampereen teknillinen yliopisto. Julkaisu-Tampere University of Technology. Publication; 1001.

Wang, W. Y., Pauleen, D. J., \& Zhang, T. (2016). How social media applications affect B2B communication and improve business performance in SMEs. Industrial Marketing Management, 54, 4-14.

Yusoff, M. N. H., Al Mamun, A., Ibrahim, M. D., \& Hassan, H. (2018). Measuring and Comparing Functional Business Skills and Knowledge among Asnaf Community in Malaysia. Economics and Sociology, 11(2), 229-247.

Zakaria, M. N., Yasoa', M. R., Ghazali, M. S., Ibrahim, M. A. H., \& Ismail, M. (2017). Integration of employee development practices and organisational performance of local government. Institutions and Economies.9(1), 61-79.

Zehir, C., Köle, M., \& Yıldız, H. (2015). The mediating role of innovation capability on market orientation and export performance: An implementation on SMEs in Turkey. Procedia-Social and Behavioral Sciences, 207, 700-708.

Zhou, L., Wu, W.-P., \& Luo, X. (2007). Internationalization and the performance of born-global SMEs: the mediating role of social networks. Journal of international business studies, 38(4), 673-690.

Zolkepli, I. A., \& Kamarulzaman, Y. (2015). Social media adoption: The role of media needs and innovation characteristics. Computers in Human Behavior, 43, 189-209.

\section{Copyrights}

Copyright for this article is retained by the author(s), with first publication rights granted to the journal.

This is an open-access article distributed under the terms and conditions of the Creative Commons Attribution license (http://creativecommons.org/licenses/by/4.0/). 